\title{
Using Matrices to Balance Chemical Reactions and Modeling the Implications of a Balanced Reaction
}

\author{
Emilee Barrett \\ University of South Florida
}

\author{
Advisors: \\ Arcadii Grinshpan, Mathematics and Statistics \\ Frankie Costanza, Chemistry \\ Problem Suggested By: Frankie Costanza
}

Follow this and additional works at: https://digitalcommons.usf.edu/ujmm

Part of the Mathematics Commons

UJMM is an open access journal, free to authors and readers, and relies on your support:

Donate Now

\section{Recommended Citation}

Barrett, Emilee (2019) "Using Matrices to Balance Chemical Reactions and Modeling the Implications of a Balanced Reaction," Undergraduate Journal of Mathematical Modeling: One + Two: Vol. 10: Iss. 1, Article 5.

DOI: https://doi.org/10.5038/2326-3652.10.1.4910

Available at: https://digitalcommons.usf.edu/ujmm/vol10/iss1/5 


\title{
Using Matrices to Balance Chemical Reactions and Modeling the Implications of a Balanced Reaction
}

\begin{abstract}
This paper explores an alternative way to balancing equations of chemical reactions and understanding why it is necessary to use balanced equations in science. To balance a chemical equation chemists often guess the coefficients that would balance the equation and check if it works. An alternative method is to use matrices to determine the coefficients of a balanced chemical reaction through solving a system of linear Diophantine equations. After determining the coefficients, a balanced chemical reaction can be formed and used to model how the different coefficients impact the overall reaction. Then it can lead to larger applications within the environment such as atmospheric pollution due to certain everyday chemical reactions.
\end{abstract}

\section{Keywords}

balanced chemical equations, matrix operations, systems of linear Diophantine equations, atmospheric pollution

\section{Creative Commons License} (c) $(i)(9)$

This work is licensed under a Creative Commons Attribution-Noncommercial-Share Alike 4.0 License. 


\section{PROBLEM STATEMENT}

Investigating how to use matrices to determine the stoichiometric values of chemical reactions and how to use a balanced chemical reaction and predetermined reactant or product quantities that can produce a model.

\section{MOTIVATION}

Everything in the universe is derived from infinite chemical reactions among various element arrangements. A chemical reaction explains, in a simple form, what occurs when certain reactants, which can be an element of molecular compound, mix with other reactants or decompose to form a product, which can be a different element or molecular compound. These reactions are commonly expressed as chemical equations with the reactants on the left side and a product on the right side with an arrow indicating the direction of the reaction. One common example is $2 \mathrm{H}_{2}+\mathrm{O}_{2} \rightarrow 2 \mathrm{H}_{2} \mathrm{O}$ which is the combination of hydrogen gas and oxygen gas to create water. Another simple example is $\mathrm{CO}_{2}+\mathrm{H}_{2} \mathrm{O} \rightarrow \mathrm{H}_{2} \mathrm{CO}_{3}$ which is the formation of carbonic acid from water and carbon dioxide. Both reactions occur naturally in the environment and can be useful along with many of the other infinite chemical reactions. However, everything is only good in moderation and abundance of carbon dioxide can damage the ocean ecosystems due to ocean acidification and over pollution. Ocean acidification is the gradual lowering of the ocean's $\mathrm{pH}$ (potential of hydrogen) due to the absorption of carbon dioxide in large quantities in the water from the atmosphere. The carbon dioxide when mixed with water creates carbonic acid which is what causes the $\mathrm{pH}$ to become more acidic (PMEL Carbon Group). The large amount of carbon dioxide in the atmosphere not only poses an issue to ocean ecosystems, but also it is a 
factor in global warming which impacts the environment on a larger scale. Carbon dioxide and other compounds pollute the atmosphere in large quantities caused by simple reactions; however, not all of the reactions are a one to one ratio like the carbonic acid. Some reactions take more reactants to yield a single compound of product; yet, other reactions take few reactants to yield multiples of the final product, for example, the creation of water. Understanding how to properly create and balance chemical equations is imperative to scientists to know how much of a product is being formed from certain reactants. Knowing how much product is formed from a certain quantity of reactants aids scientists in determining how certain reactions are polluting the environment. It also allows for the verification of how many reactants must be present to form the product.

Any balanced chemical equation must be in accordance with the Law of Conservation of Matter. The law states that " there is no detectable change in the total quantity of matter present when matter converts from one type to another or changes among solid, liquid, or gaseous states" (Flowers), hence there must be an equal number of molecules of the same species on both sides on the equation. This is done by adding the whole number of coefficients to certain molecules or compounds. When first learning how to derive and balance chemical equations most people tend to have a "guess and check" approach. They assume that a certain coefficient will balance the equation and then test to make sure the moles are equal on both sides of the equation. Not only is this method time consuming it can also lead to inaccurate answers in more complex reactions. An alternative method to determine the coefficients of the species in a chemical reaction is to use matrices. Matrices can be used to determine the balanced chemical equation of any reaction; however, this paper focuses on three reactions that involve carbon dioxide as a pollutant and shows how matrices are a more accurate approach to balance chemical equations. 


\section{MATHEMATICAL DESCRIPTION AND SOLUTION}

Matrices are used to find the coefficients (integer numbers) of multiple variables in a system of Diophantine linear equations (Lazebnik) provided that the variables and system create the square matrices. For simplicity, we consider the invertible matrices. Creating the suitable invertible matrix and vector, finding the inverse and determinant of the matrix, and then finding the overall product make possible to find the missing variables or coefficients in the original system of equations. This approach makes possible to balance chemical equations with the smallest coefficient. The balanced chemical equations and previously determined data make possible to model how not every reaction follows a 1:1 ratio, but some reactions form six times the amount of product to a single reaction. The ratio is determined by the balanced chemical formula hence it is clear why it is essential to be able to accurately form the balanced reaction. Once a chemical reaction is balanced it can be used to understand how certain quantities of the reactants and products impact one another.

To understand how to set-up the matrices, we demonstrate the simplest chemical reaction of hydrogen plus oxygen yielding water. First we write the unbalanced chemical equation with lower-case variables $(a, b$, and $c)$ to represent the balancing coefficients. Then we give a system of equations for the elements in the reaction by identifying how many molecules of the element are present on each side of the equation:

$$
a \mathrm{H}_{2}+b \mathrm{O}_{2} \rightarrow c \mathrm{H}_{2} \mathrm{O}
$$

Equation (1) implies that:

$$
H: 2 a+O b=2 c,
$$




$$
O: 0 a+2 b=1 c
$$

Using these two equations makes possible to set up two matrices. Matrix $A$ holds the left side of the reaction and matrix $B$, which is a vector, holds the right side of the equation. The first row is the first equation and the second row is the second equation, mixing up the order will result in the wrong coefficients. Additionally, we find the inverse and the determinant of matrix A (see Stewart, Appendix A):

$$
\begin{gathered}
\text { matrix } A=\left[\begin{array}{ll}
2 & 0 \\
0 & 2
\end{array}\right], \quad \text { matrix } A^{-1}=\left[\begin{array}{cc}
0.5 & 0 \\
0 & 0.5
\end{array}\right], \\
\operatorname{det}(A)=(2 \times 2)-(0 \times 0)=4, \\
\text { vector } B=\left[\begin{array}{l}
2 \\
1
\end{array}\right] .
\end{gathered}
$$

To calculate the coefficients $a$ and $b$, we multiply the inverse of matrix $A$ with vector $B$ and the determinant of matrix $A$. The final matrix gives the coefficients $a$ and $b$ respectively. Lower-case $c$ is equal to the determinant of matrix $A$ :

$$
\begin{gathered}
{\left[\begin{array}{cc}
0.5 & 0 \\
0 & 0.5
\end{array}\right] \times\left[\begin{array}{l}
2 \\
1
\end{array}\right] \times 4=\left[\begin{array}{l}
4 \\
2
\end{array}\right]=\left[\begin{array}{l}
a \\
b
\end{array}\right]} \\
c=4 \\
4 \mathrm{H}_{2}+2 \mathrm{O}_{2} \rightarrow 4 \mathrm{H}_{2} \mathrm{O}
\end{gathered}
$$

The equation above is now balanced. It can also be simplified since there is a common factor of two; therefore, when the entire equation is divided by the common factor it creates the wellknown form of $2 \mathrm{H}_{2}+\mathrm{O}_{2} \rightarrow 2 \mathrm{H}_{2} \mathrm{O}$. 
The same format works to calculate a balanced chemical equation for more complex reactions as well. The following reactions progressively become more complex and in excess they are harmful to the environment. As the reactions increase in complexity, the system of equations must be shifted so that the right side has one variable only. This is due to the necessity to determine the determinant for a square matrix. To create a square matrix more species and their coefficients are added to the left side (demonstrated below).

Chemical reaction 1:

$$
a \mathrm{O}_{2}+b \mathrm{C}_{6} \mathrm{H}_{12} \mathrm{O}_{6} \rightarrow c \mathrm{H}_{2} \mathrm{O}+d \mathrm{CO}_{2}
$$

Equation (2) implies that:

$$
\begin{gathered}
O: 2 a+6 b=1 c+2 d \rightarrow 2 a+6 b-1 c=2 d, \\
C: 0 a+6 b=0 c+1 d \rightarrow 0 a+6 b+0 c=1 d, \\
H: O a+12 b=2 c+0 d \rightarrow 0 a+12 b-2 c=0 d .
\end{gathered}
$$

We have (see Nykamp, Stewart, Appendix A):

$$
\begin{gathered}
\operatorname{matrix} A=\left[\begin{array}{ccc}
2 & 6 & -1 \\
0 & 6 & 0 \\
0 & 12 & -2
\end{array}\right], \quad \text { matrix } A^{-1}=\left[\begin{array}{ccc}
0.5 & 0 & -0.25 \\
0 & 0.166 & 0 \\
0 & 1 & -0.5
\end{array}\right], \\
\operatorname{det}(A)=2[(6 \times(-2))-(0 \times 12)]-0[\ldots]+0[\ldots]=-24, \\
\text { vector } B=\left[\begin{array}{l}
2 \\
1 \\
0
\end{array}\right] .
\end{gathered}
$$


Hence

$$
\begin{gathered}
{\left[\begin{array}{ccc}
0.5 & 0 & -0.25 \\
0 & 0.166 & 0 \\
0 & 1 & -0.5
\end{array}\right] \times\left[\begin{array}{l}
2 \\
1 \\
0
\end{array}\right] \times(-24)=\left[\begin{array}{c}
-24 \\
-4 \\
-24
\end{array}\right]=\left[\begin{array}{l}
a \\
b \\
c
\end{array}\right]} \\
d=-24 \\
-24 \mathrm{O}_{2}-4 \mathrm{C}_{6} \mathrm{H}_{12} \mathrm{O}_{6} \rightarrow-24 \mathrm{H}_{2} \mathrm{O}-24 \mathrm{CO}_{2}
\end{gathered}
$$

Again, there is a common factor but this time it is negative four. So, we divide the entire equation by negative four to yield the simplest form of the balanced equation:

$$
6 \mathrm{O}_{2}+\mathrm{C}_{6} \mathrm{H}_{12} \mathrm{O}_{6} \rightarrow 6 \mathrm{H}_{2} \mathrm{O}+6 \mathrm{CO}_{2}
$$

The equation can be used to better understand how many products are produced from the reaction given the number of reactants available. As long as one glucose mole and six moles of oxygen gas are available the body can perform cellular respiration which is the chemical equation above. The purpose of cellular respiration is to create usable energy, but it also creates two waste products; carbon dioxide and water. Knowing that the body needs at least one hundred moles of ATP, which generate the energy, for a person of fifty pounds it can be extrapolated with the body in taking three glucose moles in to live (Zimmerman). Using the same ratio, for a fivehundred-pound person, they need about ten thousand ATP moles which translate to about three hundred glucose moles. Having a minimum and maximum number of glucose molecules as reactants it is possible to create a graph of the number of moles of carbon dioxide and water generated from a set number of glucose moles when there is an unlimited source of oxygen. 


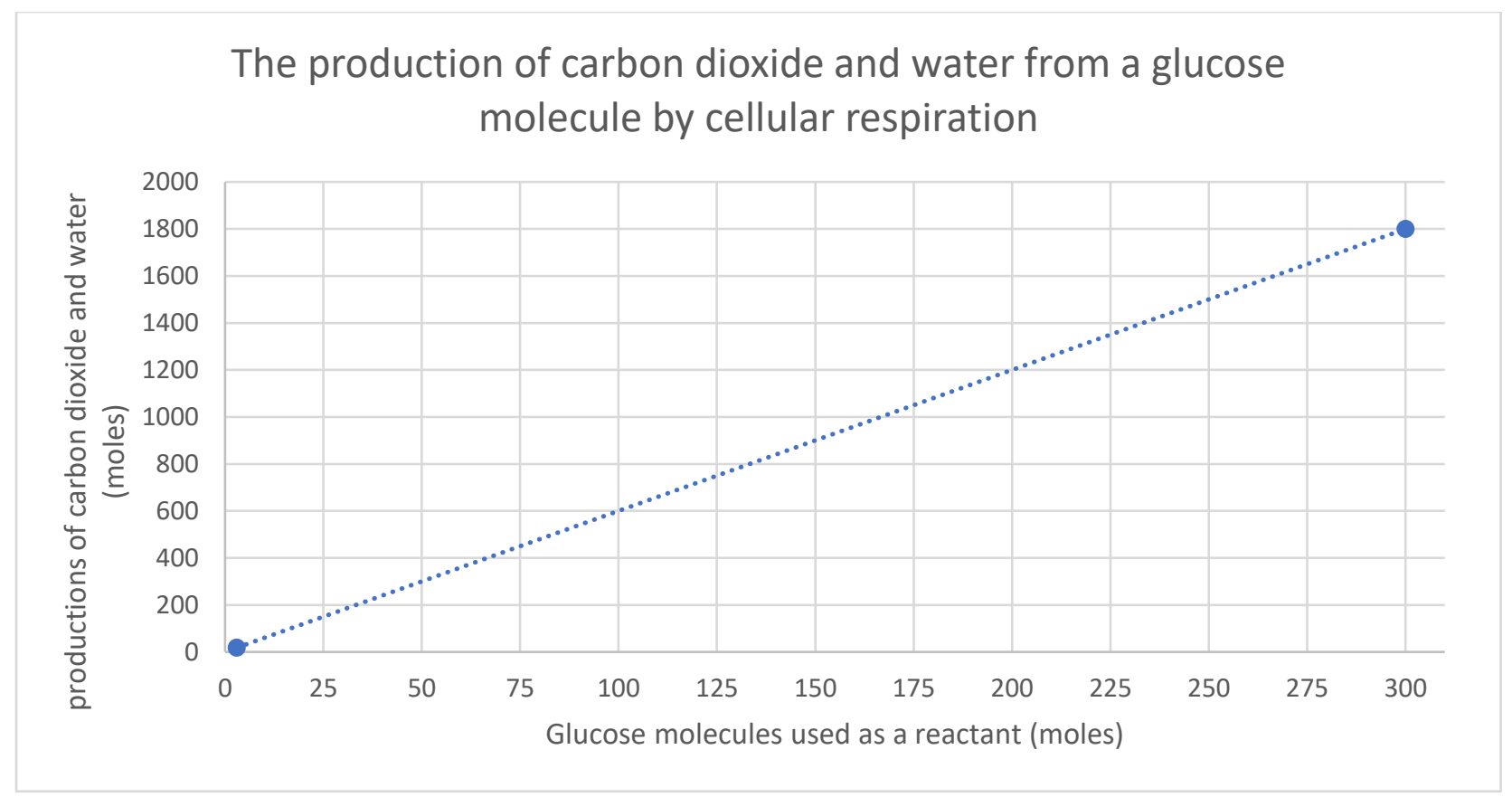

The graph depicts the trendline of how many moles of both carbon dioxide and water are generated from the combustion of a specific number of glucose molecules through cellular respiration. The line is only a trend line because no data is used to plot the points within the graph it is just a speculation based on research and it could fluctuate from person to person. However, in every person and organism that undergoes cellular respiration, the amount of carbon dioxide in moles and the amount of water in moles produced is always the same. This is because the balanced equation shows that the glucose to carbon dioxide ratio is 1:6 which is the same as the glucose to water ratio is.

Chemical reaction 2:

$$
a \mathrm{C}_{8} \mathrm{H}_{18}+b \mathrm{O}_{2} \rightarrow c \mathrm{CO}_{2}+d \mathrm{H}_{2} \mathrm{O}
$$

Equation (3) implies that:

$$
C: 8 a+0 b=1 c+0 d \rightarrow 8 a+0 b-1 c=0 d,
$$

$H: 18 a+O b=O c+2 d \rightarrow 18 a+0 b+0 c=2 d$, 


$$
O: 0 a+2 b=2 c+1 d \rightarrow 0 a+2 b-2 c=1 d .
$$

We have (see Nykamp, Stewart, Appendix A):

$$
\text { matrix } A=\left[\begin{array}{ccc}
8 & 0 & -1 \\
18 & 0 & 0 \\
0 & 2 & -2
\end{array}\right], \quad \text { matrix } A^{-1}=\left[\begin{array}{ccc}
0 & 1 / 18 & 0 \\
-1 & 4 / 9 & 0.5 \\
-1 & 4 / 9 & 0
\end{array}\right]
$$

$\operatorname{det}(A)=8[(0 \times(-2))-(0 \times 2)]-0[(18 \times(-2))-(0 \times 0)]+(-1)[(18 \times 2)-(0 \times 0)]=-36$,

$$
\text { vector } B=\left[\begin{array}{l}
0 \\
2 \\
1
\end{array}\right]
$$

Hence

$$
\begin{gathered}
{\left[\begin{array}{ccc}
0 & 1 / 18 & 0 \\
-1 & 4 / 9 & 0.5 \\
-1 & 4 / 9 & 0
\end{array}\right] \times\left[\begin{array}{l}
0 \\
2 \\
1
\end{array}\right] \times(-36)=\left[\begin{array}{c}
-4 \\
-50 \\
-32
\end{array}\right]=\left[\begin{array}{l}
a \\
b \\
c
\end{array}\right]} \\
d=-36 \\
-4 C_{8} \mathrm{H}_{18}-50 \mathrm{O}_{2} \rightarrow-32 \mathrm{CO}_{2}-36 \mathrm{H}_{2} \mathrm{O}
\end{gathered}
$$

The above equation is balanced though there is a common factor of negative two. Therefore, we divide the entire equation by negative two to yield the simplest form of the balanced equation:

$$
2 \mathrm{C}_{8} \mathrm{H}_{18}+25 \mathrm{O}_{2} \rightarrow 16 \mathrm{CO}_{2}+18 \mathrm{H}_{2} \mathrm{O}
$$

The equation above is better now as the combustion of gasoline with available oxygen yields energy, carbon dioxide and water (Kuntzleman). Using the information attained from an online data base makes possible to determine how many moles of carbon dioxide and water vapor are released into the atmosphere due to the burning of gasoline (Energy Statistics Database) (Appendix B and C). 


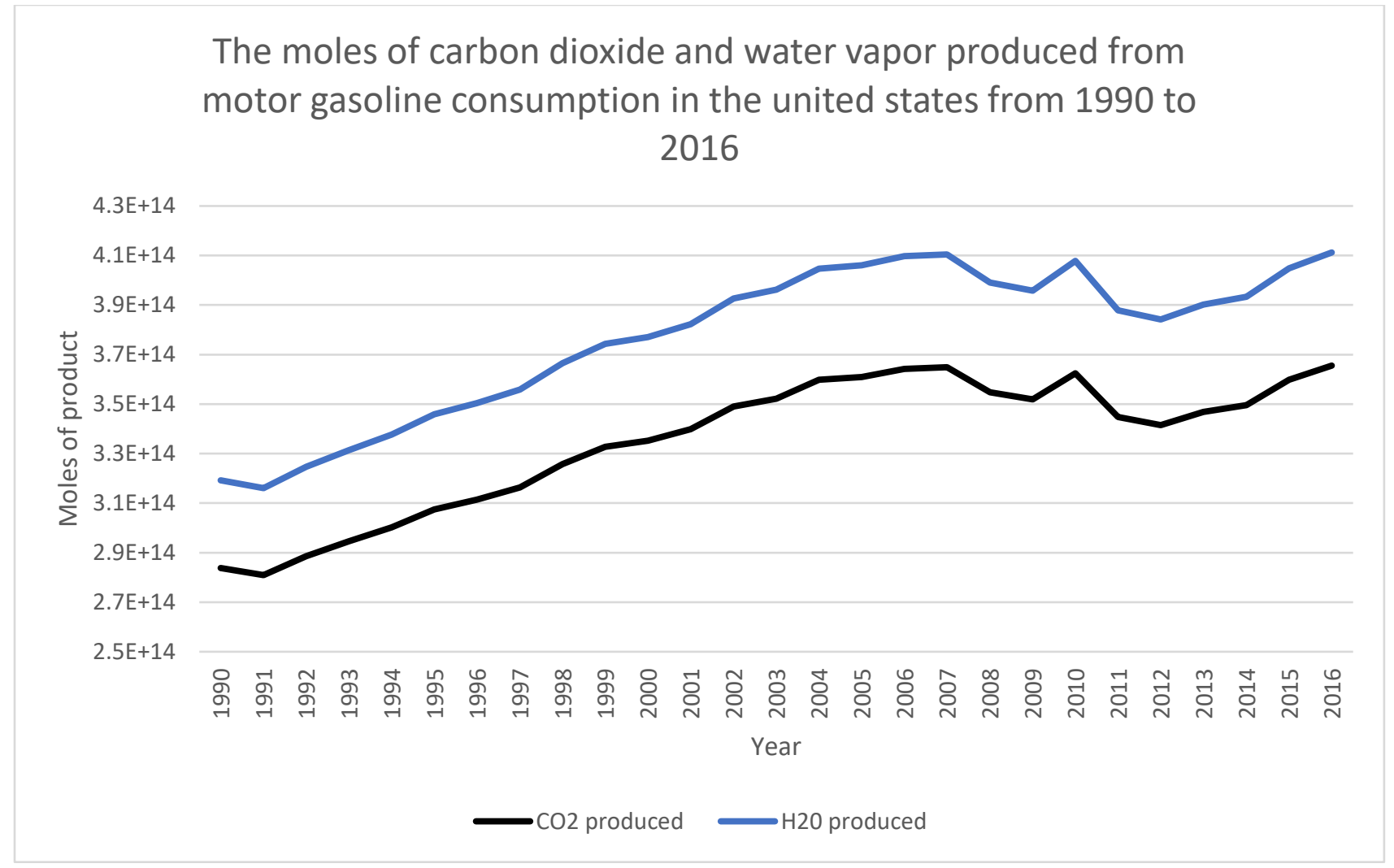

The graph above represents the moles of carbon dioxide and water vapor emitted from solely motor gasoline consumption during the years of 1990 to 2016 in the United States. The water vapor production is always higher than the carbon dioxide because it is based on the balanced chemical equation; the water has a higher coefficient meaning that eighteen moles are produced for every two moles of gasoline, as long as oxygen is available, whereas carbon dioxide yields sixteen moles per every two moles of gasoline. The graph also shows that from 1991 to about 2007 in the United States the pollution due to motor gas consumption is steadily increased. From 2007 to 2009, the pollution is decreased only to spike in 2010 and is decreased again until 2012. Since 2012, the United States has seen an increase in pollutants caused by motor gasoline consumption and it seems to be rising to a higher pollution rate than previously recorded.

Chemical reaction 3:

$$
a \mathrm{Fe}_{2} \mathrm{SiO}_{4}+\mathrm{bMg}_{2} \mathrm{SiO}_{4}+c \mathrm{H}_{2} \mathrm{O}+d \mathrm{CO}_{2} \rightarrow e \mathrm{Mg}_{6}\left(\mathrm{Si}_{4} \mathrm{O}_{10}\right)(\mathrm{OH})_{8}+\mathrm{fFe}_{2} \mathrm{O}_{3}+\mathrm{gCH}_{4}
$$


Equation (4) implies that:

$F e: 2 a+O b+O c+O d=O e+2 f+O g \rightarrow 2 a+O b+O c+O d+O e-2 f=0 g$,

Si: $1 a+1 b+0 c+0 d=4 e+O f+0 g \rightarrow 1 a+1 b+0 c+0 d-4 e+O f=0 g$,

$O: 4 a+4 b+1 c+2 d=18 e+3 f+0 g \rightarrow 4 a+4 b+1 c+2 d-18 e-3 f=0 g$,

$M g: O a+2 b+O c+O d=6 e+O f+0 g \rightarrow O a+2 b+0 c+0 d-6 e+O f=0 g$,

$H: O a+O b+2 c+O d=8 e+O f+4 g \rightarrow O a+0 b+2 c+0 d-8 e+O f=4 g$,

$C: O a+O b+O c+1 d=0 e+O f+1 g \rightarrow 0 a+0 b+0 c+1 d+0 e+0 f=1 g$.

We obtain (see Nykamp, Stewart, Appendix A):

matrix $A=\left[\begin{array}{cccccc}2 & 0 & 0 & 0 & 0 & -2 \\ 1 & 1 & 0 & 0 & -4 & 0 \\ 4 & 4 & 1 & 2 & -18 & -3 \\ 0 & 2 & 0 & 0 & -6 & 0 \\ 0 & 0 & 2 & 0 & -8 & 0 \\ 0 & 0 & 0 & 1 & 0 & 0\end{array}\right], \quad$ matrix $A^{-1}=\left[\begin{array}{cccccc}1.5 & 2 & -1 & 1 & 0.5 & 2 \\ 4.5 & 3 & -3 & 5 & 1.5 & 6 \\ 6 & 4 & -4 & 6 & 2.5 & 8 \\ 0 & 0 & 0 & 0 & 0 & 1 \\ 1.5 & 1 & -1 & 1.5 & 0.5 & 2 \\ 1 & 2 & -1 & 1 & 0.5 & 2\end{array}\right]$,

$\operatorname{det}(A)=8$,

vector $B=\left[\begin{array}{l}0 \\ 0 \\ 0 \\ 0 \\ 4 \\ 1\end{array}\right]$. 
Hence

$$
\begin{gathered}
{\left[\begin{array}{cccccc}
1.5 & 2 & -1 & 1 & 0.5 & 2 \\
4.5 & 3 & -3 & 5 & 1.5 & 6 \\
6 & 4 & -4 & 6 & 2.5 & 8 \\
0 & 0 & 0 & 0 & 0 & 1 \\
1.5 & 1 & -1 & 1.5 & 0.5 & 2 \\
1 & 2 & -1 & 1 & 0.5 & 2
\end{array}\right] \times\left[\begin{array}{l}
0 \\
0 \\
0 \\
0 \\
4 \\
1
\end{array}\right] \times 8=\left[\begin{array}{c}
32 \\
96 \\
144 \\
8 \\
32 \\
32
\end{array}\right]=\left[\begin{array}{l}
a \\
b \\
c \\
d \\
e \\
f
\end{array}\right]} \\
32 \mathrm{Fe}_{2} \mathrm{SiO}_{4}+96 \mathrm{Mg}_{2} \mathrm{SiO}_{4}+144 \mathrm{H}_{2} \mathrm{O}+8 \mathrm{CO}_{2} \rightarrow 32 \mathrm{Mg}_{6}\left(\mathrm{Si}_{4} \mathrm{O}_{10}\right)(\mathrm{OH})_{8}+32 \mathrm{Fe}_{2} \mathrm{O}_{3}+8 \mathrm{CH}_{4}
\end{gathered}
$$

The above equation is balanced though there is a common factor of eight. Therefore, we divide the entire equation by eight to yield the simplest form of the balanced equation:

$$
4 \mathrm{Fe}_{2} \mathrm{SiO}_{4}+12 \mathrm{Mg}_{2} \mathrm{SiO}_{4}+18 \mathrm{H}_{2} \mathrm{O}+\mathrm{CO}_{2} \rightarrow 4 \mathrm{Mg}_{6}\left(\mathrm{Si}_{4} \mathrm{O}_{10}\right)(\mathrm{OH})_{8}+4 \mathrm{Fe}_{2} \mathrm{O}_{3}+\mathrm{CH}_{4}
$$

The graph included below, is from the study by Yamamoto et al, "Modeling of methane bubbles released from large sea-floor area: Condition required for methane emission to the atmosphere" (Yamamoto). The graph demonstrates how the chemical reactions that occur even at a deep-sea level can impact the atmospheric conditions due to the saturation of the chemical in the water. The study does not specify the reactions pertaining to the outgassing, but it does expressive the impact of methane. 


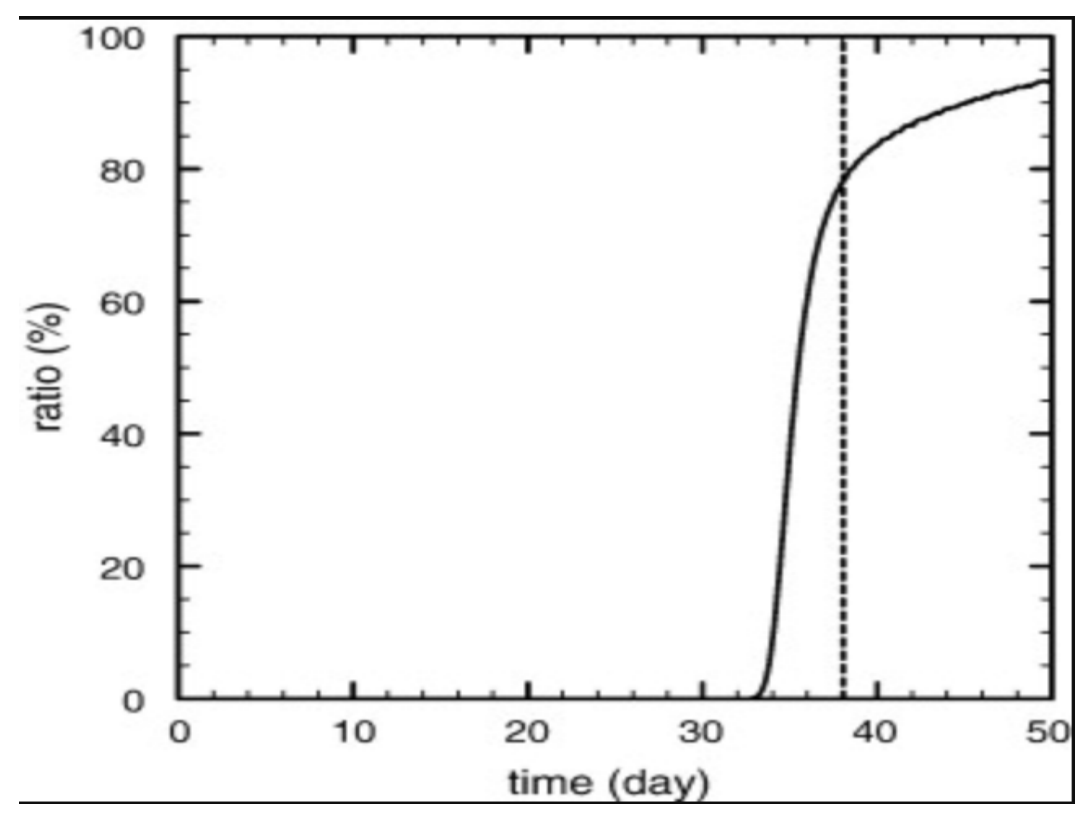

The graph displays the ratio of methane reaching the atmosphere to that released from the sea floor at a given day during the experiment. The dotted line indicates the day when the water column became saturated with methane (Yamamoto). From the graph it can be said that the more methane saturates the water, the higher the likelihood that more methane will evaporate into the atmosphere. It also shows that the water does not have to be fully saturated to release methane into the atmosphere. Therefore, it is important to reduce the amount of methane produced in the oceans so that there is a reduced likelihood of methane gas polluting the atmosphere. Overall, the study found that average ratio of methane reaching the atmosphere to the water column is $45 \%$ (Yamamoto).

\section{DISCUSSION}

To appropriately use a chemical equation, it is imperative for it to be balanced correctly. If the ratio between the species is inaccurate then what is produced may be underestimated or overestimated which is not viable in scientific investigations. In the case of environmental 
pollution, if scientists only write chemical equations as a 1:1 ratio then the amount of calculated pollutants, like carbon dioxide in the atmosphere or ocean, would always be less than the amount of carbon dioxide in the atmosphere or ocean. Matrices are an accurate way to balance complex chemical equations and are far less time consuming with the aid of a calculator than the "guess and check" method. Once the chemical equation is balanced data can be inserted into the equation to determine the effects of the reaction in terms of what is produced. It can also be graphed to show a visual representation of how the different coefficients of the products and reactants have a major impact on how much is created.

The first chemical reaction is known as cellular respiration which is carried out by most living multicellular organisms. The reaction produces water, carbon dioxide and energy by mixing oxygen gas with a glucose molecule. Though a balanced chemical reaction provides the information that in order for the reaction to take place there needs to be at least six oxygen gas molecules available per one glucose molecule. The results are more than one molecule of water and carbon dioxide; the reaction yields six molecules of water and six molecules of carbon dioxide. While the water molecules are recycled within the organism, the carbon dioxide molecules need to be released because the gas is a harmful waste product. The excreted six carbon dioxide molecules are reintroduced to the environment and can add to the overall total of pollutants in the atmosphere. Preventing cellular respiration to limit the amount of carbon dioxide in the atmosphere is unethical and inhuman; however, it does help scientists determine how much carbon dioxide in the atmosphere is due to necessary human life.

The second chemical reaction is the combustion reaction of burning gasoline. With the balanced chemical equation, it takes two moles of octane to combine with twenty-five moles of oxygen gas to produce energy along with sixteen moles of carbon dioxide and eighteen moles of 
water. Just like in cellular respiration, in most factories and machines the energy produced is the only viable product and the carbon dioxide and water are waste products. Sometimes the water is recycled but the carbon dioxide is released into the environment and adds to the pollution in the atmosphere. The increased burning of gasoline in industries and transportation is causing the amount of carbon dioxide pollution to drastically increase.

The third chemical reaction is the generation of serpentine, hematite, and methane gas within the earth's mantle and along the ocean floor because of the available carbon dioxide in the water along with fayalite and forsterite. This chemical equation is different from the previous two because instead of producing carbon dioxide as a pollutant, it uses the carbon dioxide as a reactant to make methane, another more dangerous pollutant. While understanding how much of a product is being created, it is also important to realize the number of reactants that cause the reaction to take place. Due to a balanced chemical equation, it can be seen that only one mole of carbon dioxide is needed for the reaction to take place as long as the other reactants are available. If the amount of carbon dioxide dissolved into the oceans decreased it would reduce the production of methane gas; however, it would not be a large difference because the reaction only needs one mole of carbon dioxide. Therefore, if scientists wish to reduce the amount of outgassed methane from thus chemical reaction, it would be more beneficial to focus on reducing another reactant like forsterite because the reaction requires more moles of the reactant in order to proceed forward.

\section{CONCLUSION AND RECOMMENDATIONS}

Chemical reactants help people understand how certain molecules are produced and in what quantities. It also identifies how much of the reactants are needed to carry out the reaction. 
Balancing the chemical reaction specifies these two identities of a chemical reaction and aids in understanding how to prevent or increase the process. The chemical equations highlighted in this paper, involve carbon dioxide which is an atmospheric pollutant and how various everyday occurrences increase the ratio of carbon dioxide in the atmosphere. The last equation also demonstrates an application of the carbon dioxide because as the carbon dioxide increases in the atmosphere it can diffuse into the oceans more and allow for more complex and harmful reactions to occur. The only way to understand these relationships is to have a balanced chemical equation. The primary method of assuming coefficients that could balance the equation and then testing their viability is time consuming and not always accurate. However, matrices can be used to quickly and accurately provide the coefficients per individual species for a balanced chemical reaction. 
Undergraduate Journal of M athematical M odeling: One + Two, Vol. 10, Iss. 1 [2019], Art. 5

NOMENCLATURE

\begin{tabular}{|l|l|}
\hline $\mathrm{H}_{2}$ & Hydrogen gas \\
\hline $\mathrm{O}_{2}$ & Oxygen gas \\
\hline $\mathrm{H}_{2} \mathrm{O}$ & Dihydrogen monoxide, water \\
\hline $\mathrm{CO}_{2}$ & Carbon dioxide \\
\hline $\mathrm{H}_{2} \mathrm{CO}_{3}$ & Carbonic acid \\
\hline $\mathrm{C}_{6} \mathrm{H}_{12} \mathrm{O}_{6}$ & Glucose \\
\hline $\mathrm{ATP}$ & Adenosine triphosphate \\
\hline $\mathrm{C}_{8} \mathrm{H}_{18}$ & Octane \\
\hline $\mathrm{Fe}_{2} \mathrm{SiO}_{4}$ & Fayalite \\
\hline $\mathrm{Mg}_{2} \mathrm{SiO}_{4}$ & Forsterite \\
\hline $\mathrm{Mg}_{6}\left(\mathrm{Si}_{4} \mathrm{O}_{10}\right)(\mathrm{OH})_{8}$ & Serpentine \\
\hline $\mathrm{Fe}_{2} \mathrm{O}_{3}$ & Iron (III) oxide, Hematite \\
\hline $\mathrm{CH}_{4}$ & Methane \\
\hline
\end{tabular}




\section{APPENDIX}

Appendix A: formulas to determine the determinant of a matrix

Determinant of a $2 \times 2$ matrix $A=\left\{a_{j l}\right\}\left(a_{11}=a, a_{12}=b, a_{21}=c, a_{22}=\right.$ d) (Stewart and Day):

$$
a d-b c
$$

Determinant of a $3 \times 3$ matrix $A=\left\{a_{j l}\right\}$

$\left(a_{11}=a, a_{12}=b, a_{13}=c, a_{21}=d, a_{22}=e, a_{23}=f, a_{31}=g, a_{32}=h, a_{33}=i\right)$ (Nykamp, Stewart and Day):

$$
a(e i-f h)-b(d i-f g)+c(d h-e g)
$$

Determinant of a $6 \times 6$ matrix $A=\left\{a_{j l}\right\}(j, l=1,2,3,4,5,6)$ (Dragovitsch, Nykamp):

$$
\sum_{l=1}^{6} a_{j l} C_{j l},
$$

where $\mathrm{j}$ can be any row subscript between 1 and $6 ; C_{j l}=(-1)^{j+l} M_{j l} ; M_{j l}$ is the determinant of the submatrix of the original matrix $A=\left\{a_{j l}\right\}$ obtained by eliminating row $j$ and column $l$ (the minor). 
Undergraduate Journal of M athematical M odeling: One +Two, Vol. 10, Iss. 1 [2019], Art. 5

Appendix B: Motor gasoline consumption database (Energy Statistics Database)

\begin{tabular}{|c|c|c|c|c|}
\hline United States & Motor Gasoline - Final consumption & 2016 & Metric tons, thousand & 400,307 \\
\hline United States & Motor Gasoline - Final consumption & 2015 & Metric tons, thousand & 394,081 \\
\hline United States & Motor Gasoline - Final consumption & 2014 & Metric tons, thousand & 382,883 \\
\hline United States & Motor Gasoline - Final consumption & 2013 & Metric tons, thousand & 379,760 \\
\hline United States & Motor Gasoline - Final consumption & 2012 & Metric tons, thousand & 373,950 \\
\hline United States & Motor Gasoline - Final consumption & 2011 & Metric tons, thousand & 377,601 \\
\hline United States & Motor Gasoline - Final consumption & 2010 & Metric tons, thousand & 396,938 \\
\hline United States & Motor Gasoline - Final consumption & 2009 & Metric tons, thousand & 385,333 \\
\hline United States & Motor Gasoline - Final consumption & 2008 & Metric tons, thousand & 388,469 \\
\hline United States & Motor Gasoline - Final consumption & 2007 & Metric tons, thousand & 399,561 \\
\hline United States & Motor Gasoline - Final consumption & 2006 & Metric tons, thousand & 398,909 \\
\hline United States & Motor Gasoline - Final consumption & 2005 & Metric tons, thousand & 395,206 \\
\hline United States & Motor Gasoline - Final consumption & 2004 & Metric tons, thousand & 394,000 \\
\hline United States & Motor Gasoline - Final consumption & 2003 & Metric tons, thousand & 385,644 \\
\hline United States & Motor Gasoline - Final consumption & 2002 & Metric tons, thousand & 382,285 \\
\hline
\end{tabular}

\begin{tabular}{|c|c|c|c|c|}
\hline United States & Motor Gasoline - Final consumption & 2001 & Metric tons, thousand & 372,126 \\
\hline United States & Motor Gasoline - Final consumption & 2000 & Metric tons, thousand & 367,082 \\
\hline United States & Motor Gasoline - Final consumption & 1999 & Metric tons, thousand & 364,363 \\
\hline United States & Motor Gasoline - Final consumption & 1998 & Metric tons, thousand & 356,758 \\
\hline United States & Motor Gasoline - Final consumption & 1997 & Metric tons, thousand & 346,401 \\
\hline United States & Motor Gasoline - Final consumption & 1996 & Metric tons, thousand & 341,071 \\
\hline United States & Motor Gasoline - Final consumption & 1995 & Metric tons, thousand & 336,703 \\
\hline United States & Motor Gasoline - Final consumption & 1994 & Metric tons, thousand & 328,700 \\
\hline United States & Motor Gasoline - Final consumption & 1993 & Metric tons, thousand & 322,576 \\
\hline United States & Motor Gasoline - Final consumption & 1992 & Metric tons, thousand & 315,999 \\
\hline United States & Motor Gasoline - Final consumption & 1991 & Metric tons, thousand & 307,662 \\
\hline United States & Motor Gasoline - Final consumption & 1990 & Metric tons, thousand & 310,766 \\
\hline
\end{tabular}


Barrett: Using M atrices to Balance Chemical Reactions and M odeling the Imp

Appendix C: Calculations to derive moles from the database

\begin{tabular}{r|r|r|}
\hline Year & CO2 produced & H20 produced \\
\hline 1990 & $2.83777 \mathrm{E}+14$ & $3.19249 \mathrm{E}+14$ \\
\hline 1991 & $2.80942 \mathrm{E}+14$ & $3.1606 \mathrm{E}+14$ \\
\hline 1992 & $2.88555 \mathrm{E}+14$ & $3.24625 \mathrm{E}+14$ \\
\hline 1993 & $2.94561 \mathrm{E}+14$ & $3.31381 \mathrm{E}+14$ \\
\hline 1994 & $3.00153 \mathrm{E}+14$ & $3.37672 \mathrm{E}+14$ \\
\hline 1995 & $3.07461 \mathrm{E}+14$ & $3.45894 \mathrm{E}+14$ \\
\hline 1996 & $3.1145 \mathrm{E}+14$ & $3.50381 \mathrm{E}+14$ \\
\hline 1997 & $3.16317 \mathrm{E}+14$ & $3.55856 \mathrm{E}+14$ \\
\hline 1998 & $3.25774 \mathrm{E}+14$ & $3.66496 \mathrm{E}+14$ \\
\hline 1999 & $3.32719 \mathrm{E}+14$ & $3.74309 \mathrm{E}+14$ \\
\hline 2000 & $3.35202 \mathrm{E}+14$ & $3.77102 \mathrm{E}+14$ \\
\hline 2001 & $3.39808 \mathrm{E}+14$ & $3.82284 \mathrm{E}+14$ \\
\hline 2002 & $3.49084 \mathrm{E}+14$ & $3.9272 \mathrm{E}+14$ \\
\hline 2003 & $3.52152 \mathrm{E}+14$ & $3.96171 \mathrm{E}+14$ \\
\hline 2004 & $3.59782 \mathrm{E}+14$ & $4.04755 \mathrm{E}+14$ \\
\hline 2005 & $3.60883 \mathrm{E}+14$ & $4.05994 \mathrm{E}+14$ \\
\hline 2006 & $3.64265 \mathrm{E}+14$ & $4.09798 \mathrm{E}+14$ \\
\hline 2007 & $3.6486 \mathrm{E}+14$ & $4.10467 \mathrm{E}+14$ \\
\hline 2008 & $3.54731 \mathrm{E}+14$ & $3.99073 \mathrm{E}+14$ \\
\hline 2009 & $3.51868 \mathrm{E}+14$ & $3.95851 \mathrm{E}+14$ \\
\hline 2010 & $3.62465 \mathrm{E}+14$ & $4.07773 \mathrm{E}+14$ \\
\hline 2011 & $3.44807 \mathrm{E}+14$ & $3.87908 \mathrm{E}+14$ \\
\hline 2012 & $3.41473 \mathrm{E}+14$ & $3.84157 \mathrm{E}+14$ \\
\hline 2013 & $3.46779 \mathrm{E}+14$ & $3.90126 \mathrm{E}+14$ \\
\hline 2014 & $3.4963 \mathrm{E}+14$ & $3.93334 \mathrm{E}+14$ \\
\hline 2015 & $3.59856 \mathrm{E}+14$ & $4.04838 \mathrm{E}+14$ \\
\hline 2016 & $3.65541 \mathrm{E}+14$ & $4.11234 \mathrm{E}+14$ \\
\hline & & \\
\hline & & \\
\hline 14 &
\end{tabular}




\section{REFERENCES}

Peter Dragovitsch, Ben A Fusaro. "Determinants. Cramers Rule.” Florida State University Department of Mathematics, FSU, 2000; www.math.fsu.edu/ fusaro/EngMath/Ch6/DCR.html. Energy Statistics Database. "UNdata | Record View | Motor Gasoline.” United Nations, 28 Jan. 2018, data.un.org/Data.aspx?d=EDATA\&f=cmID:MO.

Paul Flowers, Klaus Theopold, Richard Langley, William Robinson.

Chemistry. 7th ed., OpenStax, 2015.

Tom Kuntzleman. "Chemical Connections to Climate Change." Chemical Education Xchange, Weebly, 25 Jan. 2017; www.chemedx.org/blog/chemical-connections-climate-change.

Felix Lazebnik. “On Systems of Linear Diophantine Equations.” Mathematics Magazine, Vol. 69, no. 4, 261-266, 1996.

D.Q. Nykamp. "Matrices and determinants for multivariable calculus.” From Math Insight; http://mathinsight.org/matrices_determinants_multivariable_calculus

PMEL Carbon Group. “Ocean Acidification: The Other Carbon Dioxide Problem.” Center for Environmental Visualization; www.pmel.noaa.gov/co2/story/Ocean Acidification.

James Stewart, Troy Day. Biocalculus: Calculus, Probability, and Statistics for the Life Sciences, Cengage Learning, 2016.

A.Yamamoto, Y. Yamanaka, E. Tajika. "Modeling of methane bubbles released from large seafloor area: Condition required for methane emission to the atmosphere." ScienceDirect, Earth and Planetary Science Letters, Vol. 284, Issues 3-4, 590-598, 2009; www.sciencedirect.com/science/article/pii/S0012821X09003136.

Jerry J. Zimmerman, Amélie von Saint André-von Arnim, Jerry McLaughlin. “Cellular Respiration." Adenosine Triphosphate - an Overview | ScienceDirect Topics, Pediatric Critical Care (4th Edition), 2011; www.sciencedirect.com/topics/neuroscience/adenosine-triphosphate. 